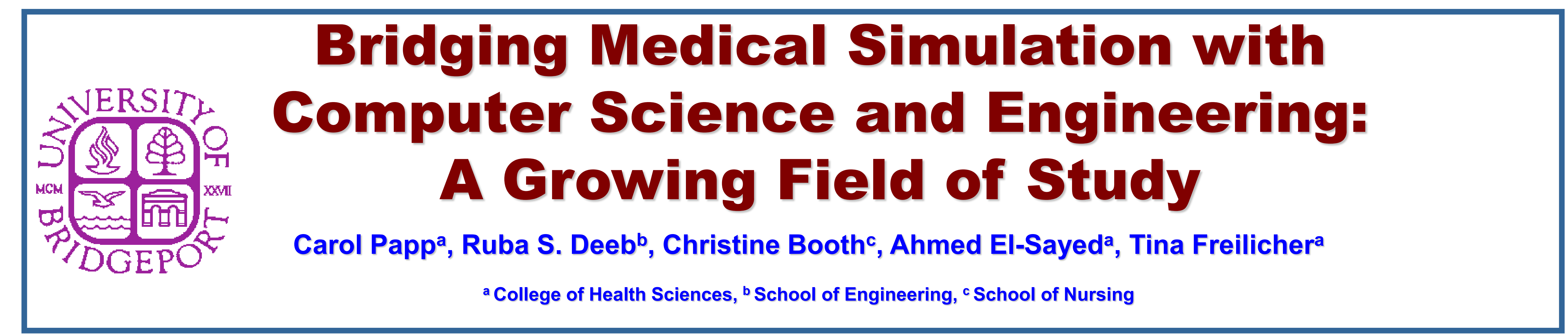

\begin{abstract}
Objectives: The aim of this study was to determine if having on-site technological expertise will allow for the facile navigation of high fidelity manikins within nursing programs as well as to assess if the level of understanding and interest among engineering students would increase as a result of attending a class related to the technology used in healthcare simulation.

Methods: Two assessments were applied to engineering students attending a class on technology used in healthcare simulation. A pre-test was designed to measure the understanding and interest of students in the engineering/computer science courses before attending a simulation class. A post-test assessment was used to measure their improvement in understanding and interest to learn more about simulation technologies.

Participants: Engineering students attending 6 different engineering programs (Computer Science, Computer Engineering, Mechanical Engineering, Biomedical Engineering, Electrical Engineering and Technology Management) and having different educational levels (undergraduate and graduate).
\end{abstract}

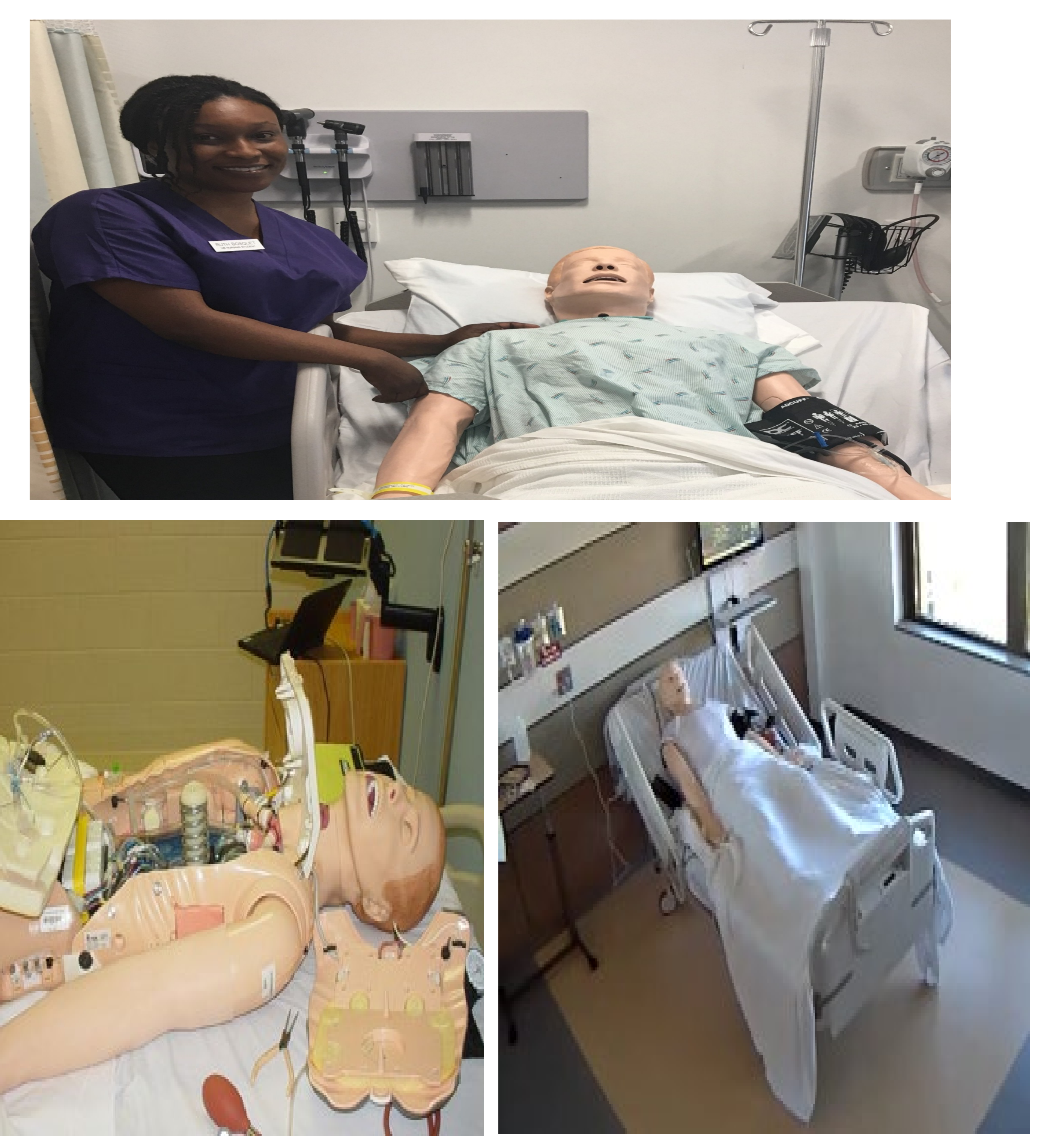

\section{Survey Questions}

Perceptions of Healthcare Simulation Learning and Level of Interest in Healthcare Simulation Learning

\begin{tabular}{l} 
Interest in Healthcare Simulation Learning \\
\hline 1.1 have a general understanding of simulation learning in the healthcare industry.
\end{tabular}

2. I am able to summarize the benefins of simulation-based learning.

3. I am able to summarize the limitations of simulation-based learning.

4. II am able to differentiate between various types of simulation equipment.

6. Il am able to identify various virtual learning emironments used in the practice of clinical scenarios.

7.I am interested in learring more about simultation in healthcare

2. Il am interested in learning more about the software used in simulation learning.

2. || am interested in learning more about the hardware used in simulation learning.

10. II am aware of employment opportunities in simulation learning in the heathcare industry.

Cother (please specifin)

\section{Results}

Table 1. A) Pre- and Post-Test Survey Statements about Perceptions of, and Level of Interest in, Healthcare Simulation Learning, B) Agreement Rating Scale

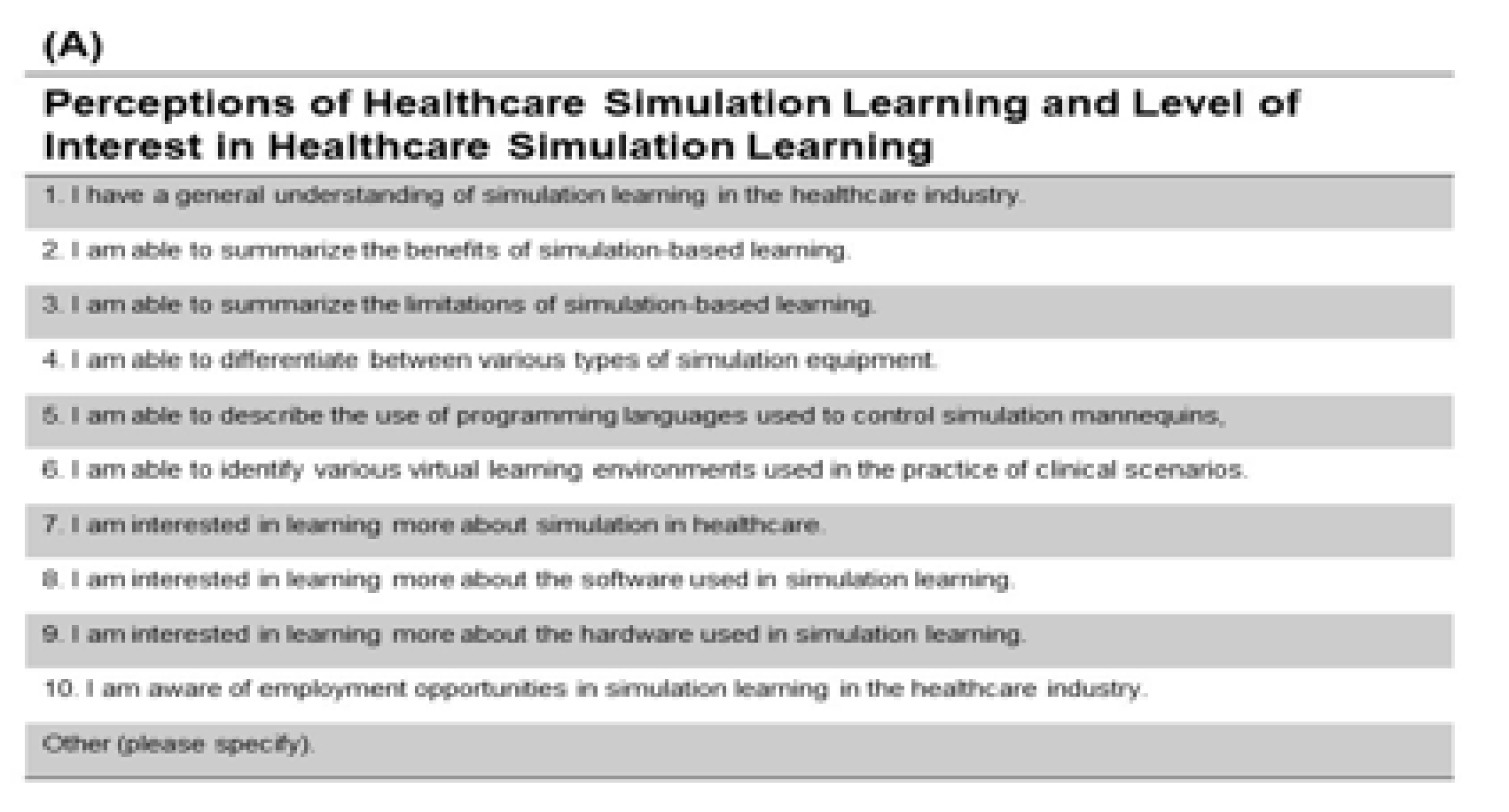
(B)

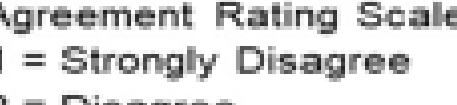
$3=$ Agree
$4=S t r o n g l y$
Agree
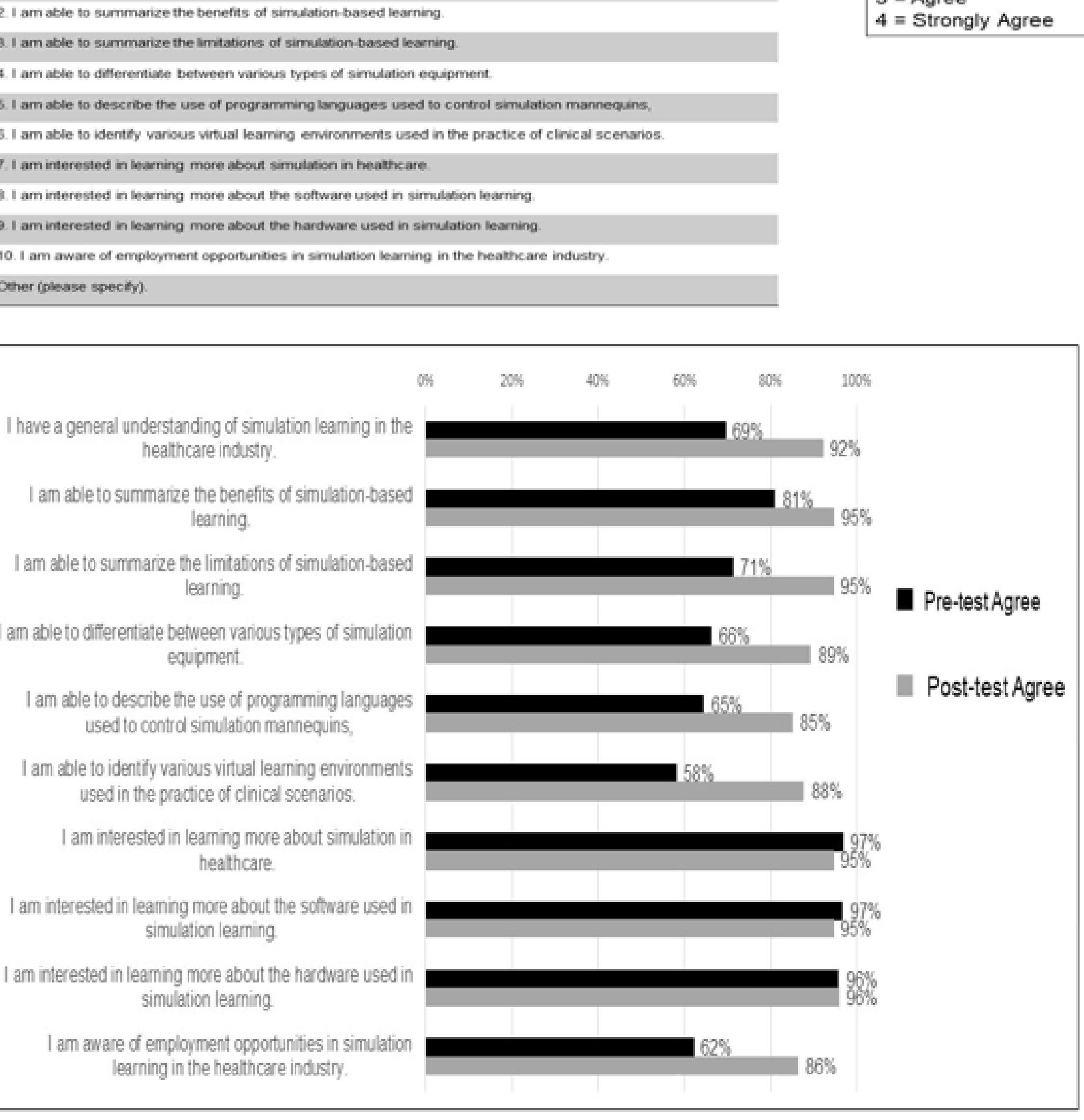

Figure 1. Pre-and Post-Testhealthcare Simulation Learning Perceptions: percentages of "agree" "ratings from computer science and engineering studentis who attended a heatticare simulation learning class and that completed a pre-test $(n=103)$ and postitest $(n=76)$ sunvey. (n) is number of participants.
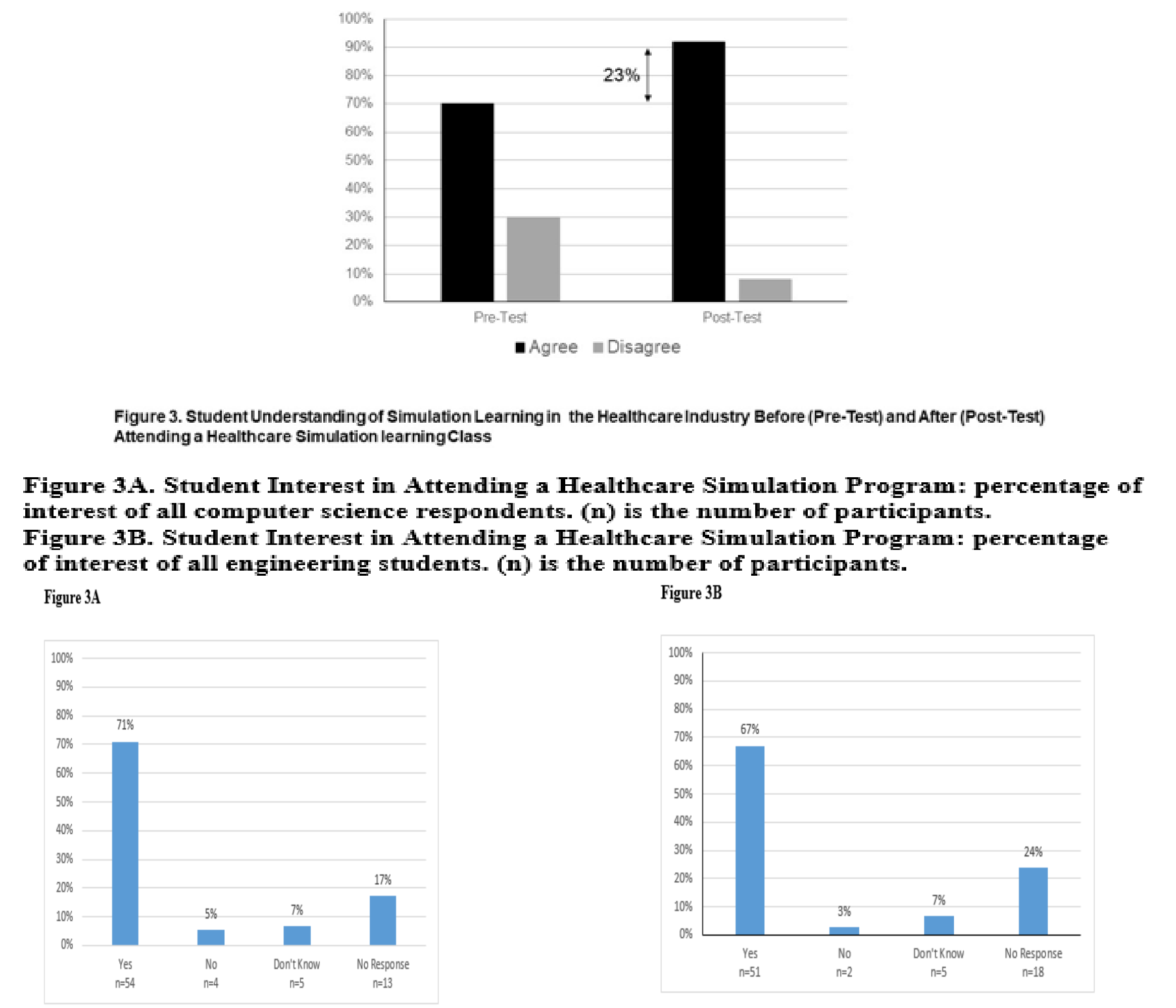

Conclusion

- A significant technological knowledge barrier exists which interferes with

maximizing the utility of simulation by healthcare professionals.

- This barrier stems from a shortage of engineering professionals with specific

training in simulation to team with healthcare professionals.

- A strategy to address this barrier is to educationally prepare engineering students to provide this dedicated technological support with an understanding of medical terminology and clinical scenarios implemented in the varied healthcare education programs across the country. 